\title{
ICRC confirms validity of the recognition granted by it to the Lithuanian Red Cross Society on 28 August 1923
}

\author{
Circular No. 558
}

Geneva, 20 November 1991

\author{
To the Central Committees of the National Red Cross \\ and Red Crescent Societies
}

\section{Ladies and Gentlemen,}

We have the honour of informing you that the International Committee of the Red Cross has confirmed its recognition of the Lithuanian Red Cross Society, originally granted on 28 August 1923. This decision, which took effect on 7 November 1991, brings to 149 the number of National Societies that are members of the International Red Cross and Red Crescent Movement.

The Lithuanian Red Cross Society, which was founded in 1919, was incorporated into the Alliance of Red Cross and Red Crescent Societies of the USSR when the Baltic countries were made part of the Soviet Union in 1940.

On 19 October 1991, the Lithuanian Red Cross Society officially requested confirmation of its previous recognition by the International Committee of the Red Cross. In support of its request it forwarded several documents, including the text of its statutes and a copy of an official note from the Lithuanian government recognizing the Lithuanian Red Cross Society as auxiliary to the public authorities in the humanitarian field.

These documents, which we examined in conjunction with the Secretariat of the League of Red Cross and Red Crescent Societies, showed that the ten conditions for recognition laid down in Article 4 of the Movement's Statutes have been fulfilled.

Regarding the first condition, the Republic of Lithuania's declaration of independence in the spring of 1990 was recognized in September 1991 both by the USSR and by the rest of the international community. The Lithuanian Red Cross Society is therefore clearly constituted on the territory of an independent State.

On 10 October 1991, the Lithuanian government confirmed to the Swiss Federal Council, the depositary of the Geneva Conventions, that it was still bound by the Geneva Conventions of 27 July 1929, which had been ratified by Lithuania on 27 February 1939. 
Furthermore, during the joint ICRC/League mission to Lithuania from 15 to 24 September 1991, representatives of the two institutions ascertained that the Lithuanian Red Cross Society has a sound structure enabling it to extend its activities throughout the national territory. It is currently conducting these activities in several spheres: first aid, assisting elderly people, recruiting blood donors and tracing missing persons.

The Lithuanian Red Cross Society is presided over by Mr. Juozas Shakopa. It has its headquarters in Vilnius, at the following address:

\section{Lithuanian Red Cross Society \\ Gediminio Ave 3a \\ 232600 Vilnius}

The International Committee of the Red Cross is pleased to welcome the Lithuanian Red Cross Society back into the International Red Cross and Red Crescent Movement and to accredit it and commend it, by this circular, to all other National Societies. The ICRC extends its sincere good wishes to the Society for its future and for the success of its humanitarian work.

FOR THE INTERNATIONAL COMMITTEE

OF THE RED CROSS

Cornelio Sommaruga

President 